\title{
Continuous Landslide Early Warning Signal Capturing using IoT based Soil Pressure Monitoring Device
}

\author{
B.A.Hadi ${ }^{1,2 *}$, Afiqah Izzati Azmi Hisham ${ }^{1}$, Mat Nor Mohamad Ismail ${ }^{3}$, Z.Fairul ${ }^{1}$, M.J.MD Noor ${ }^{2,4}$, Syed \\ Abdul Mutalib Al Junid ${ }^{5,6}$ \\ ${ }^{1}$ Faculty of Civil Engineering, UniversitiTeknologi MARA, Permatang Pauh, Pulau Pinang, MALAYSIA \\ ${ }^{2}$ Geotechnical Forensics Engineering \& Investigation Research Group (GEOFORENSIC), Faculty of Civil \\ Engineering, UniversitiTeknologi MARA, Shah Alam, Selangor, MALAYSIA \\ ${ }^{3}$ Centre of Diploma Studies (CDS), Universiti Malaysia Perlis (UniMAP), Perlis, Malaysia. \\ ${ }^{4}$ Faculty of Civil Engineering, UniversitiTeknologi MARA, Shah Alam, Selangor, MALAYSIA \\ ${ }^{5}$ Electronic Architecture and Application Research Group (EArA), Faculty of Electrical Engineering, \\ UniversitiTeknologi MARA, Shah Alam, Selangor, MALAYSIA \\ ${ }^{6}$ Faculty of Electrical Engineering, UniversitiTeknologi MARA, Shah Alam, Selangor, MALAYSIA \\ *Corresponding Author: B.A.Hadi, \\ *Email: basharudin@uitm.edu.my
}

\begin{abstract}
Numerous of approach and research have been proposed to capture the early warning signal of landslide globally. Although the soil pressure monitoring is the best approach to capture the landslide early warning signal, the issue of data collection and communication between the pressure meter and analyst is the main constraint in the current technology. Therefore, this paper proposed the soil pressure monitoring with the new improved data communication as to detect any landslide early warning signal continuously without required human intervention for collecting the data. The main objective is to design, develop and test the soil pressure monitoring system using the latest Internet of Things (IoT) technology for solving the existing issues including timely and late sensing. Recent development in the field has been used as to identify the gaps and challenges in the study before the system was developed. The system comprises of BMP180 pressure sensor, NodeMCU controller and Blynx application platform. Moreover, the performance of the system was tested according to the standard via exposing the system at different moisture content and depth of the soil. The comparison between the recorded data in the real soil pressure test were used to validate the performance of the system. As conclusion, the system able to operate at the same level of sensitivity with better connectivity for high stream data towards better sensing and decision taken.
\end{abstract}

Key words : landslide, IoT, slope monitoring

\section{INTRODUCTION}

Landslide or slope failure incident is not a new issue in
Malaysia which occupying about $330200 \mathrm{~km} 2$ and located in the Southeast of Asia. According to [1], there are 600 deaths was recorded since 1961 due to frequent incident of landslide with 1990s being considered as the beginning of the period when landslides or hill slope problems gained notoriety. It is recorded that the most land-slide-prone areas are in Kuala Lumpur $(19.2 \%)$ and Selangor $(16.6 \%)$, followed by Perak with (13.4\%) and Pahang about (12.3\%) [1]. In this era, landslide occurs due to several factors such as stability of slope, climate change, human factor, and others.

On the other hand, the weather is unpredictable thus anything danger could be appeared especially during high rainfall. Consequently, the soil probably has low stability since the soil has been forced due to seepage water and erosion of the surface of slopes due to flowing of water that has high surface runoff and infiltration. Therefore, observation of the pressure parameters in soil is very important as to detect this phenomenon.

Previously, there are several sensor devices that has been used to detect and measure the pressure failure such as Fiber Bragg Grating (FBG), MPS-6 Decagon Devices and CPS120 which incorporated with Arduino UNO. According to [2], the Fiber Bragg Grating has been employed for the safety monitoring of underground diaphragm wall in the foundation of pit excavation of subway station of Metro Line.

Meanwhile, [3] mentioned that the effective solution supposed to have balance between accuracy, cost-effectiveness, simple maintenance, and installation. Moreover, [4] also emphasis on high quality, low cost, and range of solution. Both of the developed solutions proposed by [3] and [4] are for the research purpose and the sensor is very difficult to get in the market due to the high demand. 
On the other hand, the data logger is the main important components to be connected to the sensor for monitoring and further rechecked on slope failure. Not only as an interface, but the data logger also works to collect the continuous data from the sensor. Pasqualli in [5] proposed to use Raspberry-Pi as data logger to record the locomotor activities from polar invertebrates at natural state. Based on research done by [6], they are using Arduino as data logger for photovoltaic monitoring in remote area and developing countries due to the low cost. On the other hand, numerous other projects proposed of using Arduino as data logger and controller for monitoring as reported and used in [7]-[13].

Thus, this paper describes on identifying the sensor and data logger that is suitable for detecting pressure parameter and store data from a sensor in the soil. Moreover, by installing the IoT based communication device the data can be easily captured and analysed. As a solution, we propose the IoT based pressure sensor system to keep track the changes and measure the pressure parameter in soil.

\section{METHODOLOGY}

Three stages of work have been adopted to accomplish the work proposed in this study. This include identification of the sensor system and component; installation and testing; and performance evaluation and analysis.

\subsection{Identification of the Sensor System and Component}

In this stage, the selection was made based precision, cost, and availability of the component in the market. The comparative over the other research also conducted as to provide the compatibility of the sensor and data logger for the application. Moreover, the evaluation also considers the sensor application in the research or commercialization.

\subsection{Installation and Testing}

The system will be developed using the selected sensor, data logger and controller from the stage 1. Moreover, the flow of the system development is shown in Figure 1.

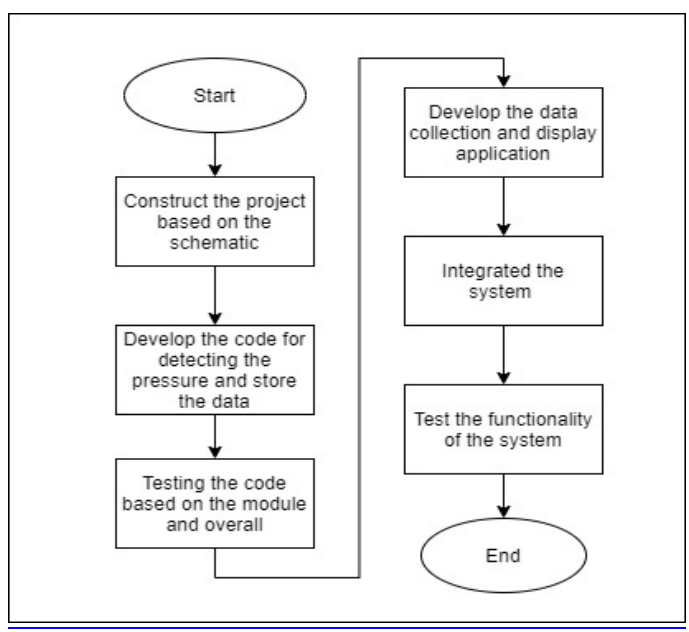

Figure 1: The flow of the system development
As depicted in Figure 1, the sensor, data logger and controller will be assemble based on the project schematic. It follows by, developing the code for sensing the pressure and to store the data. Then, both module and complete code will be tested at this point. It followed by, the development of the application to display and to collect the pressure data from the constructed system. Next, the integration between the system and application will be tested. Finally, the functionality test will be conducted as to ensure the system work according to the specification required in slope failure monitoring

\subsection{Performance Evaluation \& Analysis}

The performance evaluation was conducted in this stage. A complete process flow of the experimental setup is shown in Figure 2.

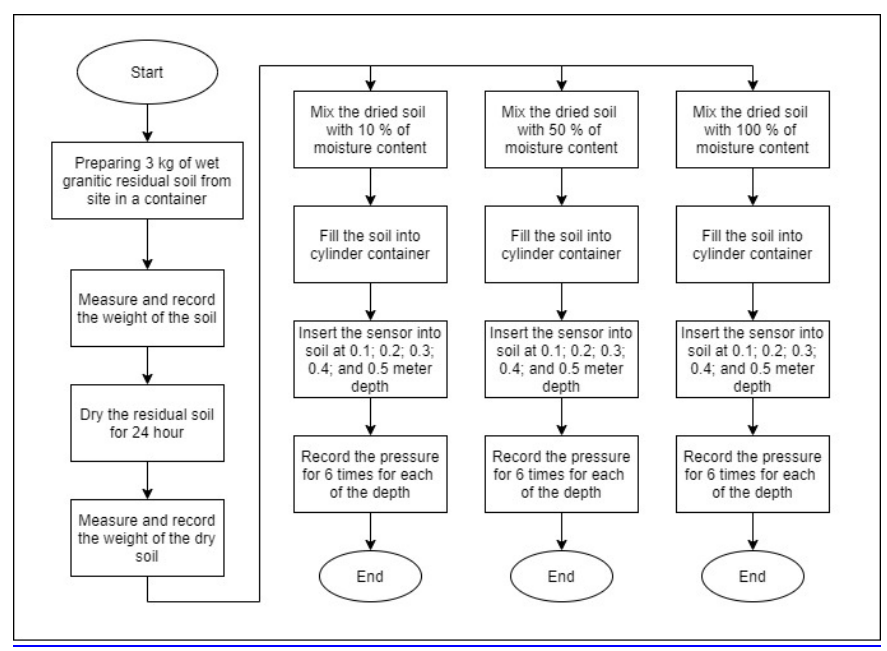

Figure 2: Experimental setup for landslide pressure signal monitoring at different moisture content and depth.

As depicted in Figure 2, three kilogram $(\mathrm{kg})$ of wet granitic residual soil from site required in this experiment. The weight of the soil and container were measured and recorded. Then, the granitic residual soil will be dried for 24 hours. After that, the weight will be measured and recorded again for dried condition. Later, mixed the dried soil with $10 \%$ of moisture content and filled the soil into the cylinder container. Then followed by inserted the sensor into the soil at $0.1 \mathrm{~m}$ depth. The procedure was repeated six times and continued with different depth starting from $0.2 \mathrm{~m}, 0.3 \mathrm{~m}, 0.4 \mathrm{~m}$, and $0.5 \mathrm{~m}$. The testing was continued for $50 \%$ and $100 \%$ of moisture content. The data was recorded via serial monitor or Blynk application. A graph of pressure versus depth of soil for $10 \%$, $50 \%$ and $100 \%$ of moisture content were plotted.

\section{RESULT AND DISCUSSION}

\subsection{Identification of the Sensor System and Component}

The sensor has been selected to be used in developing the landslide monitoring system is shown in Figure 3. 


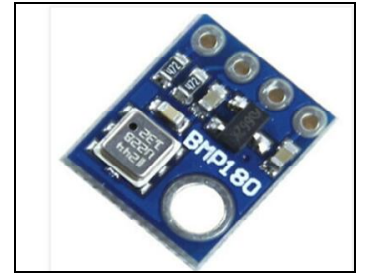

Figure 3: BMP180 Digital Barometric Pressure Sensor

As depicted in Figure 3, the BMP180 Digital Barometric Pressure Sensor has been chosen due to the sufficient level of pressure to handle, easier to get and reasonable cost. On top of that, BMP180 had several features which were low power consumption mode, high linear mode, compact size and consist of the I2C interface.

Moreover, the suitable data logger shield has been selected at this stage as shown Figure 4.

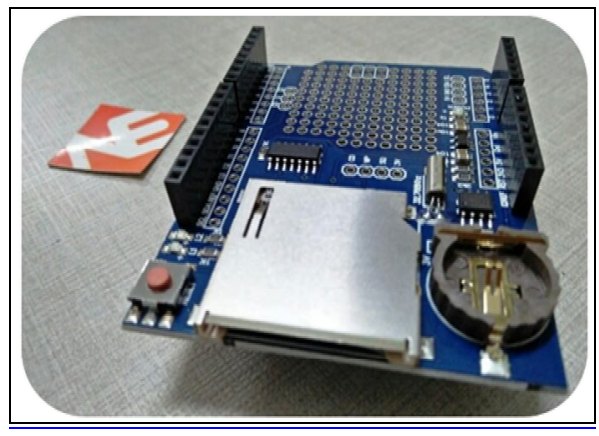

Figure 4: Shield Data logger with DS1307

As depicted in Figure 4, the data logger shield with DS1307 has been chosen based on the compatibility, reasonable price, and easy to get. It was also had some other feature which better than the other data logger. These data logger required memory card to store the data. Moreover, it also required lithium battery CR1220 for the Real-Time Clock (RTC). On the other hand, the main control is the main important component required in this project. The NodeMCU ESP8266 was selected and used in this project as shown in Figure 5.

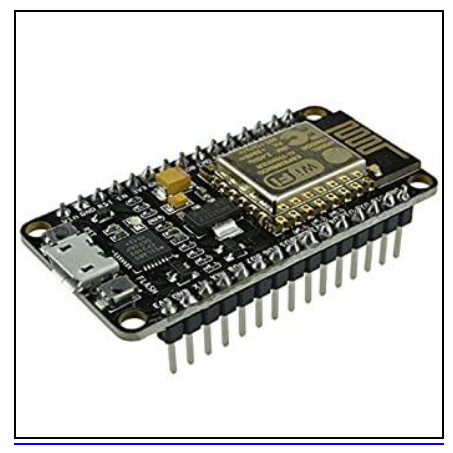

Figure 5: NodeMCU ESP8266

As shown in Figure 5, the NodeMCU ESP8266 has been chosen based on the IoT compliance device, compatibility, low power, and low cost. The NodeMCU is a low-cost IoT platform. Moreover, the NodeMCU ESP8266 required
Arduino IDE software and Blynk to accomplish the software development function shown in.

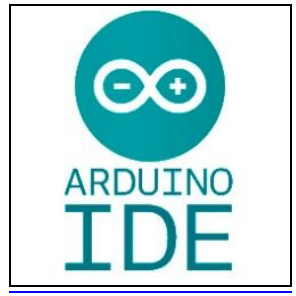

Figure 6: Arduino IDE software

As shown in Figure 6, the tool is for designer to create, compile and upload the code to any Arduino compliance devices including the NodeMCU ESP8266. Moreover, the project required the tools to connect and read the data from the NodeMCU8266 for display and data transfer purposes without any wired connection. Therefore, the Blynk has been chosen to comply the requirement.

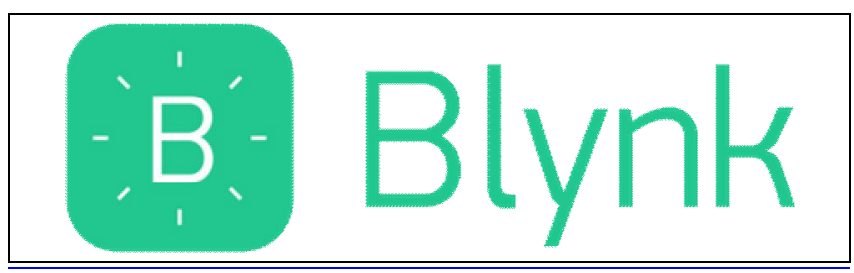

Figure 7: Blynk IoT platform

As shown in Figure 7, Blynk is a hardware-agnostic IoT platform with white-label mobile apps, private clouds, device management, data analytics, and machine learning.

\subsection{Installation and Testing}

The installation and testing were divided into two parts which are hardware and software.

A) Hardware development

The hardware development starts with assemble the sensor, datalogger and controller based on the schematic diagram of the project as shown in Figure 8.

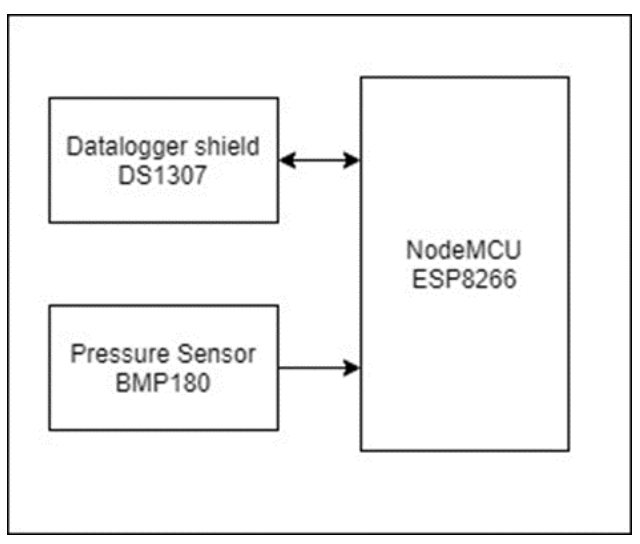

Figure 8: Schematic diagram of the project

As shown in Figure 8, the project only involved three main components which are NodeMCU ESP8266; pressure sensor 
BMP180; and datalogger shield DS1307. The complete assemble of the hardware is shown in Figure 9.

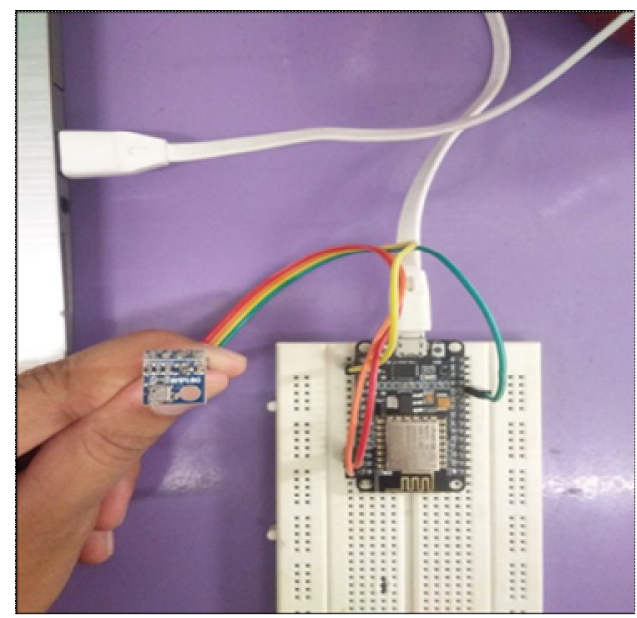

Figure 9: Complete hardware component assembles

As shown in Figure 9, the hardware component had been setting up and ready to apply on the soil. The NodeMCU was connected via USB cable to the laptop. Meanwhile, the pressure sensor was connected the NodeMCU via jumper cable from the breadboard.

\section{B) Software Development}

The software development to comprises of two part which are hardware and IoT interface part. The code initialization for the hardware part is shown in Figure 10.

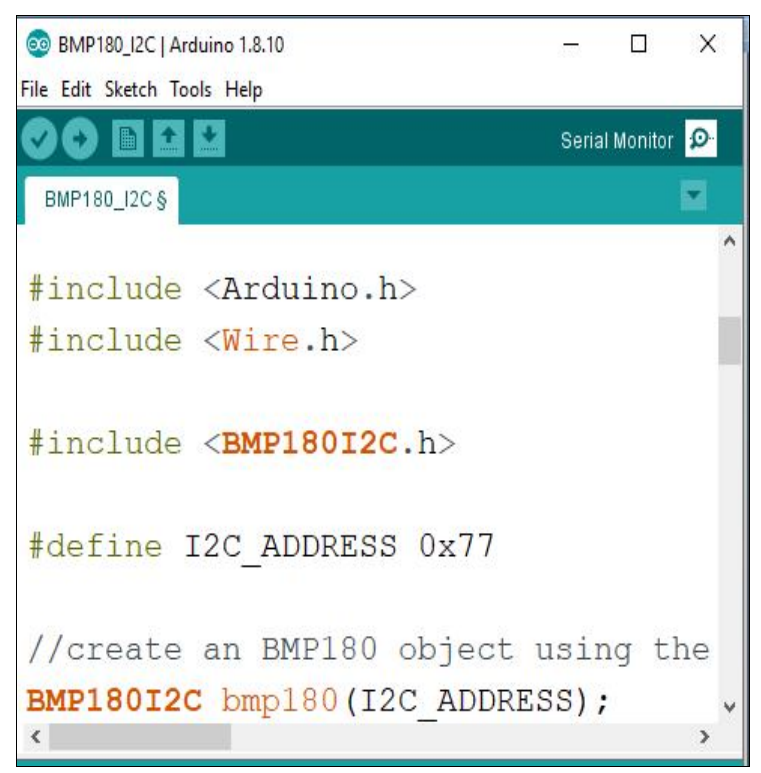

Figure 10: Complete code initialization

As depicted in Figure 10, the complete code will be uploaded to the NodeMCU after it had been verified and compiled. The verified and compiled need to be done for avoiding any functionality and code error from occurred. Moreover, the pressure data collected from the BMP180 can be seen and observed via serial monitor display in the computer.

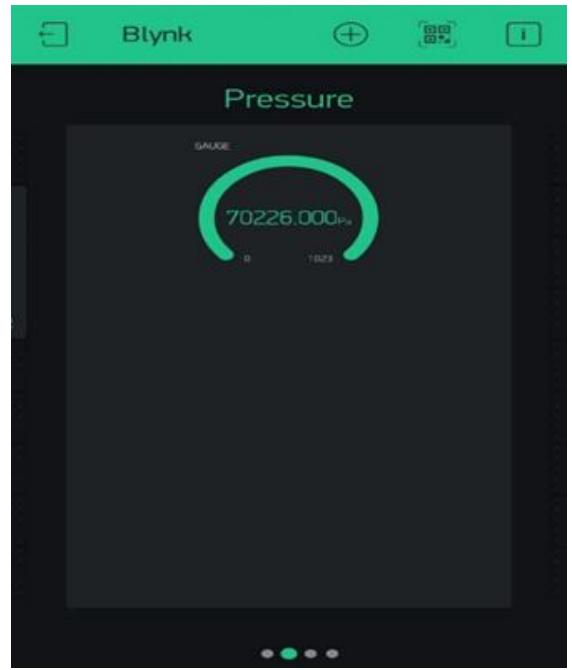

Figure 11: Application Blynk in mobile phone

As shown in Figure 11, the complete Blynk application in the mobile phone display the recorded data transferred from the NodeMCU. The result obtained from the serial communication were then compared with the data display in the Blynk application for validation purposes. Moreover, the gauge appeared in the Blynk shown the same value recorded by serial communication and data-logger. Furthermore, the Blynk used to display the value from sensor and can be read from anywhere. On top of that, the Blynk can be used to monitor the slope effectively thus reduced slope failure. It can be also notified the user if something dangerous occurred. Therefore, the authority can be aware and find solution to the problems that occurred thus reduce the number of accident and death.

\subsection{Analyse Data from IoT Device}

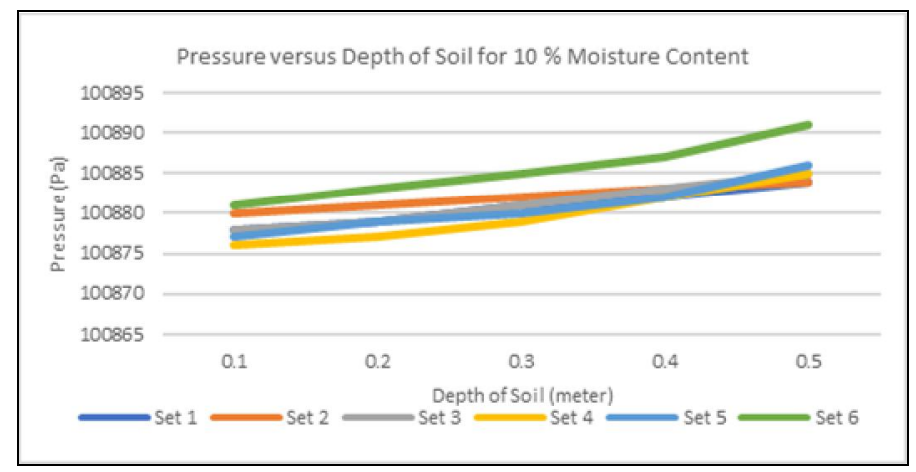

Figure 12: Pressure based on the depth of soil for $10 \%$ moisture content

As depicted in Figure 12, the pressure increased as the depth of soil increased for the $10 \%$ moisture content. Moreover, the pressure recorded shows the same pattern for each of the set. On the other hand, we can summarize that the slope tended to be stable due to less of water content at $10 \%$ moisture content. At this range, the engineer or responsible authority no need to be worried since it did not show any overshot pressure. 


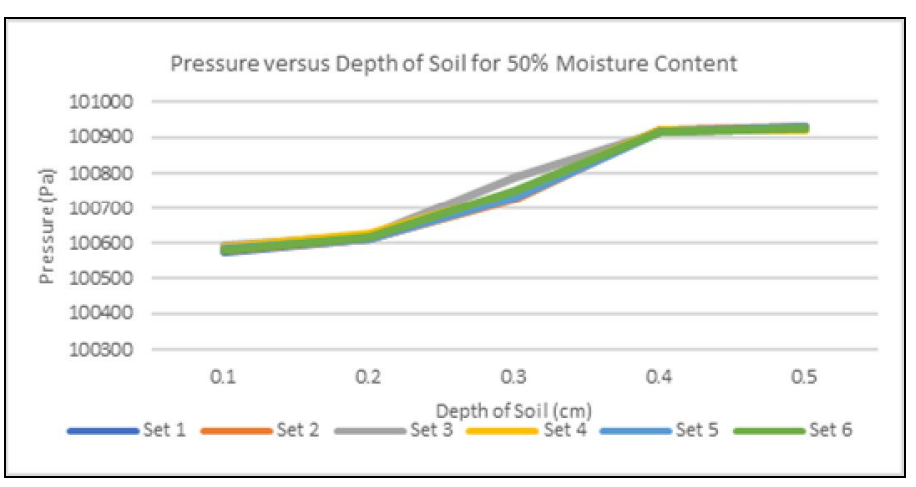

Figure 13: Pressure based on the depth of soil for $50 \%$ moisture content

As depicted in Figure 13, the pressure at range between $0.2 \mathrm{~m}$ to $0.4 \mathrm{~m}$ tended to have sudden increase due to high pressure that occurred in soil. At this state of $50 \%$ moisture content, the slope became at medium risk as the water content moderate. Therefore, the responsible engineer or authority needed to be aware as soon as they got notification through Blynk on this mode of slope.

Unfortunately, when the sensor needed to be tested for $100 \%$ of moisture content, there is no measurement verified and it seems like the slope failure had occurred. Based on the result from BMP180, the slope tended to be failed regarding to high moisture content thus gave high pressure to soil.

\section{CONCLUSION}

As a conclusion, the landslide signal monitoring based on the BMP180 pressure sensor is work well via integration with the IoT solution. Moreover, the pressure result monitored tally with the direct measured and transmitted pressure data via IoT platform. Moreover, the authority can get notification on slope mode through Blynk and can start to create awareness for other safety thus avoiding workers from any risk. In addition, the previous data of slope monitoring can be obtained from SD Card that installed in data logger DS1307 for further checking and research.

\section{ACKNOWLEDGEMENT}

The authors acknowledge the Ministry of Education Malaysia for the funding of Fundamental Research Grant Scheme (FRGS) (File No: FRGS/1/2018/TK08/UITM/02/3) received for this research. The authors also would like to thank the Research Management Center, UiTM and Faculty of Civil Engineering, UiTM.

\section{REFERENCES}

1. Bujang, B. K. (2008). Landslides in Malaysia: Occurrences, Assessment, Analysis and Remediation. Penerbitan Universiti Putra Malaysia , 406-421.
2. Ren, G., Li, T., Hu, Z., \& Zhang, C. (2019). Research on new FBG soil pressure sensor and its application in engineering. Optik, 185(122), 759-771. https://doi.org/10.1016/j.ijleo.2019.03.019

3. Rocchi, I., Gragnano, C. G., Govoni, L., Mentani, A., Bittelli, M., Castiglione, P., ... Gottardi, G. (2018). A new technique for deep in situ measurements of soil water retention behaviour. Geotechnical Research, 5(1), 3-12. https://doi.org/10.1680/jgere.17.00012

4. Ventures, D. T. (2016, June 29). Hackster.io - Pressure Measurement Using CPS120 and Arduino Nano. Retrieved November 9, 2019, from Hackster.io: https://www.hackster.io/Dcube/pressure-measurement-u sing-cps120-and-arduino-nano-1cbf4c

5. Pasquali, V., D'Alessandro, G., Gualtieri, R., \& Leccese, F. (2017). A new data logger based on Raspberry-Pi for Arctic Notostraca locomotion investigations. Measurement: Journal of the International Measurement Confederation, 110, 249-256. https://doi.org/10.1016/j.measurement.2017.07.004

6. Fuentes, M., Vivar, M., Burgos, J. M., Aguilera, J., \& Vacas, J. A. (2014). Design of an accurate, low-cost autonomous data logger for PV system monitoring using Arduino $^{\mathrm{TM}}$ that complies with IEC standards. Solar Energy Materials and Solar Cells, 130, 529-543. https://doi.org/10.1016/j.solmat.2014.08.008

7. Ahmad Faizal Zainal Abidin, Mohammad Huzaimy Jusoh, Elster James, Syed Abdul Mutalib Al Junid, Ahmad Ihsan Mohd Yassin, Real-Time Remote Monitoring with Data Acquisition System. IOP Conference Series: Materials Sciences and Engineering 99 p1-7, 2015

8. Bakri, N. A. M.; Al Junid, S. A. M.; Razak, A. H. A.; Idros, M. F. M.; Halim, A. K., Mobile carbon monoxibe monitoring system based on Arduino-Matlab for environmental monitoring application. IOP Conference Series: Materials Sciences and Engineering 99 p1- 10, 2015

9. Ussdek M. E. M., Al Junid S. A. M., Majid Z. A., Osman F. N. and Othman Z. HighSensitivity Gas Detection and Monitoring System for High-Risk Welding Activity. Proc. 2013 IEEE Conf. on Systems, Process \& Control (ICSPC) p256-261, 2013

10. Tahir N. A. M., Al Junid S. A. M., Othman Z., Abd Majid Z. and Thani S. K. S. O. Design Automatic Meter Reading (AMR) Data Logger with Xbee. International Journal of Simulation: Systems, Science and Technology 13 67-73, 2012

11. Othman N., Manan M. I. A., Othman Z., Al Junid S.A.M., Performance analysis of dualaxis solar tracking system. Proc. IEEE Int. Conf. on Control System, Computing and Engineering (ICCSCE 2013) p370-375, 2013

12. Husin R., Al Junid S. A. M., Abd Majid Z., Othman Z., Md Shariff K. K., Hashim H. and Saari M. F. Automatic Street Lighting System for Energy Efficiency Based on Low Cost Microcontroller. International Journal of 
B.A.Hadi et al., International Journal of Emerging Trends in Engineering Research, 8(10), October 2020, 6732 - 6737

Simulation: Systems, Science and Technology 13 29-34, 2012

13. Rashid Z.A., Thani S.K.S.O., Al Junid S.A.M. Trees' cooling effect on surrounding air temperature monitoring system: Implementation and observation. International Journal of Simulation: Systems, Science and Technology 15 70-77, 2014 